\title{
Timing of spawning and fecundity of a tropical and subtropical anemonefish (Pomacentridae: Amphiprion) on a high latitude reef on the east coast of Australia
}

\author{
Darren L. Richardson*, Peter L. Harrison, Vicki J. Harriott \\ Centre for Coastal Management, Southern Cross University, PO Box 157, Lismore, New South Wales 2480, Australia
}

\begin{abstract}
The timing of spawning and fecundity of the anemonefishes Amphiprion latezonatus Waite and $A$. akindynos Allen were monitored over a 1 yr period at Julian Rocks, a subtropical rocky reef located on the east coast of Australia. The tropical species A. akindynos had a shorter spawning season than the subtropical endemic species A. latezonatus, although peak spawning activity in both species occurred during the warmest time of the year. Despite having a shorter spawning season than tropical congeners, both species had the highest fecundity of anemonefishes studied to date. Both species displayed weak lunar spawning periodicity; A. akindynos had slightly more spawnings in the lunar quarters before and after the full moon than the quarters before and after the new moon, whereas $A$. latezonatus had significantly fewer spawnings in the lunar quarter before the full moon than during the other 3 lunar quarters. The spawning patterns of A. akindynos and A. latezonatus were more similar to A. clarkii in temperate Japan than to congeners in tropical regions, suggesting that environmental factors associated with high latitude environments may modify the reproductive biology of anemonefishes.
\end{abstract}

KEY WORDS: Lunar and seasonal spawning patterns $\cdot$ Anemonefish $\cdot$ Reproduction

\section{INTRODUCTION}

The timing of spawning and fecundity of Amphiprion anemonefishes has been investigated at several tropical localities (Allen 1975, Ross 1978, Fricke in Thresher 1984) and in the warm temperate seas of Japan (Bell 1976, Ochi 1985). These studies indicate that anemonefish assemblages in temperate regions of Japan have spawning periods and fecundity that are substantially different from congeners in tropical waters (Moyer 1980). Anemonefishes in tropical regions typically have a year-round non-seasonal spawning pattern (Allen 1975, Ross 1978), whereas temperate Japanese populations of Amphiprion clarkii

- Present address: WBM Oceanics, PO Box 203, Spring Hill, Queensland 4004, Australia.

E-mail: dlrichardson@wbmpl.com.au have a short intense summer breeding season (Bell 1976. Ochi 1985). Despite the short breeding season, temperate $A$. clarkii assemblages have the highest fecundity of anemonefish studied to date (Bell 1976, Ochi 1985). Tropical anemonefishes appear to have a strong lunar, or semi-lunar, periodicity in the timing of spawnings (Allen 1975, Ross 1978, Fricke in Thresher 1984). By contrast, temperate A. clarkii assemblages display weak lunar spawning patterns that are inconsistent between years and localities (Bell 1976, Ochi 1985).

It has been speculated that the short spawning season, weak lunar spawning rhythms and high fecundity of temperate Japanese Amphiprion clarkii assemblages are local adaptations to highly seasonal and severe winter water temperatures (Bell 1976, Moyer 1980). If local environmental controls caused these patterns, then other high latitude anemonefish assem- 
blages should display spawning patterns that are more consistent with congeners in temperate Japan than those in tropical localities. The study aims to describe the timing of spawning and fecundity of a tropical and. a subtropical species of anemonefish at a high latitude locality on the east coast of Australia, to determine whether: (1) spawnings follow seasonal patterns, (2) spawnings are synchronised to lunar phases, and (3) fecundity of temperate species is higher than that of tropical congeners.

\section{MATERIALS AND METHODS}

Reproduction of anemonefish was studied from November 1993 to February 1995 at Julian Rocks $\left(28^{\circ} 36^{\prime} \mathrm{S}, 153^{\circ} 37^{\prime} \mathrm{E}\right)$, located on the southeast coast of Australia (Fig. 1). Julian Rocks consists of a group of 4 islets located $2 \mathrm{~km}$ off the northern New South Wales coastline (Richardson et al. 1997). Two species of anemonefishes cooccur at this locality: the widely distributed tropical Amphiprion akindynos, and a species endemic to the eastern Australian subtropics, A. latezonatus.

All anemonefishes were mapped within a $15000 \mathrm{~m}^{2}$ area located on the west side of Julian Rocks, and all adult pairs were examined for the presence of eggs over time. The timing of egg surveys was based on the positive linear relationship between embryo development time and water temperature (Bell 1976 , D. Richardson unpubl.). Since the incubation time of eggs at water temperatures $<22^{\circ} \mathrm{C}$ was 10 to $12 \mathrm{~d}$, surveys were conducted every 8 to $10 \mathrm{~d}$ at these water temperatures (June to November 1994). During summer (temperatures $-22^{\circ} \mathrm{C}$ ), incubation times of embryos were around 6 to 9 d (D. Richardson unpubl.), thus surveys were conducted every $6 \mathrm{~d}$ from November to June. The regularity of surveys allowed

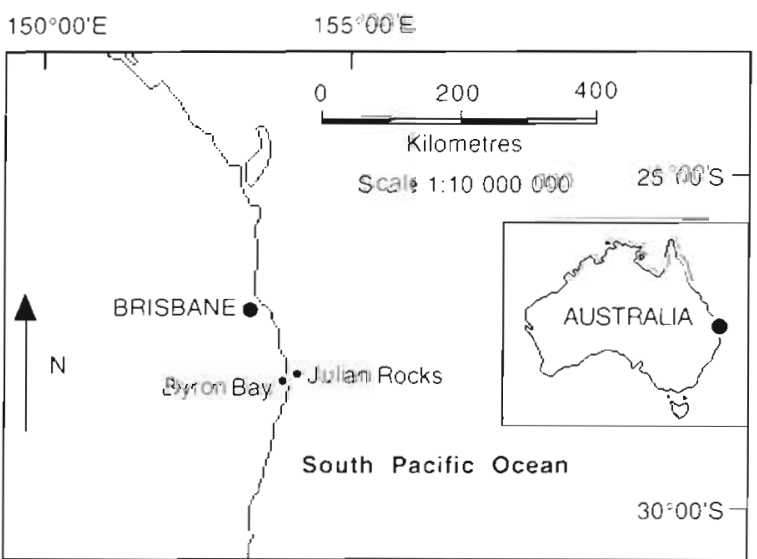

Fig. 1. Julian Rocks locality map all egg clutches to be examined at least once during their development.

The age of eggs was estimated by examining the colour and morphology of eggs (Ross 1978) relative to ambient water temperature. Since the deposition area of egg clutches was roughly circular, the maximum and minimum diameters of egg clutches were measured with a plastic ruler and the deposition area calculated using $\pi r^{2}$ (Robertson et al. 1988). Gaps in the deposition area were measured in the same way and subtracted from the total deposition area. The total number of eggs per clutch was estimated by counting all eggs within 4 replicate $0.25 \mathrm{~cm}^{2}$ quadrats, and then multiplying the egg density per $\mathrm{cm}^{2}$ by the deposition area. Total counts were conducted on clutches that had sparse or low numbers of eggs. Since some egg mortality may have occurred by the time eggs were observed, fecundity estimates may in some cases underestimate the total number of eggs produced.

To determine whether anemonefishes followed lunar or semi-lunar spawning patterns, the frequency of spawning within each quarter of the lunar cycle was compared using $\chi^{2}$, to test the null hypothesis that the frequency of spawning did not vary significantly among lunar phases.

\section{RESULTS}

\section{Breeding seasons}

The length of the spawning season varied between anemonefish species and among breeding pairs of fish. Egg clutches of Amphiprion latezonatus were recorded in every lunar month, although the total number of clutches declined in the cooler months (Fig. 2). The length of the breeding season varied among $A$. latezonatus pairs from 2 to 11 lunar months ( $\mathrm{n}=5$ pairs, mean $=5.2 \mathrm{mo} \pm 1.22 \mathrm{SE}$ ) (Fig. 3). A. akindynos had a shorter spawning season, extending from November to May-July (Figs. 2 \& 3). Water temperatures during this period ranged from 19 to $26^{\circ} \mathrm{C}$. The length of breeding season was highly variable among $A$. akindynos pairs (Fig. 3), ranging from 1 to 7 lunar months ( $\mathrm{n}=14$ to 15 pairs, mean $=3.1 \mathrm{mo} \pm 0.53 \mathrm{SE}$ )

\section{Lunar spawning cycles}

The total number of spawnings of Amphiprion latezonatus within each quarter of the lunar month is shown in Table $1 \mathrm{~A}$. The total number of spawnings was approximately equal for the first, second and fourth quarters, while there were very few in the third quarter (the quarter following the full moon). The dis- 


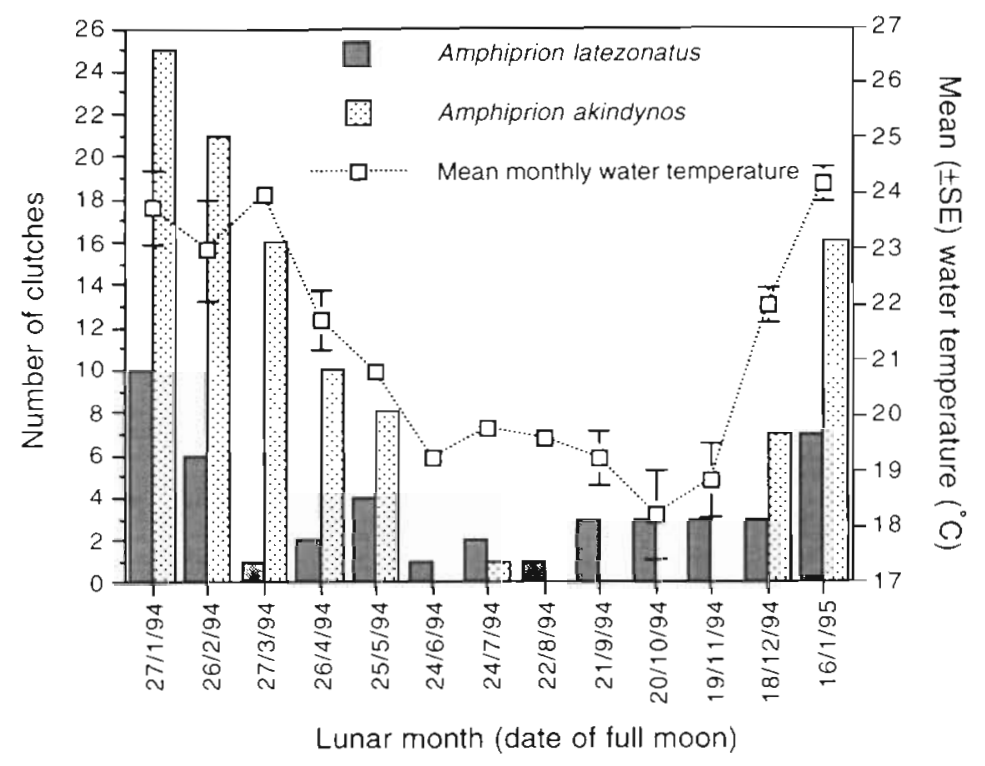

Fig. 2. Mean monthly water temperature (error bars show \pm SE) and the total number of Amphiprion latezonatus and A. akindynos egg clutches observed over 13 lunar months at Julian Rocks. The number of breeding pairs observed with eggs ranged from 0 to 15 in $A$. akindynos and 1 to 5 in A. latezonatus

tribution of the total number of spawnings in quarters of the lunar month was significantly different from an equal distribution ( $\mathrm{df}=3, \chi^{2}=8.933, \mathrm{p}<0.05$ ). Females spawned 0 to 3 times within a lunar month, at approximately semi-monthly intervals in summer months (December to April) and at monthly and bi-monthly intervals in cooler months (May to November; Table 1A).

In contrast to Amphiprion latezonatus, the most $A$. akindynos spawnings (Table $1 B$ ) were observed during the third lunar quarter (the lunar quarter following the full moon). There was no significant difference in observed and expected number of spawnings among the 4 lunar quarters $\left(\mathrm{df}=3, \chi^{2}=5.488, \mathrm{p}>0.05\right)$, however there were significantly more spawnings in the Iunar quarters before and after the full moon pooled compared to the lunar quarters before and after the new moon pooled $\left(\mathrm{df}=1, \chi^{2}=4.845, \mathrm{p}<0.03\right.$ ). Consistent with results for $A$. latezonatus, $A$. akindynos pairs spawned 0 to 3 times in a lunar month at semi-monthly intervals during December to April, and at approximately monthly intervals during the remainder of the spawning season (Table 1B).

\section{Fecundity}

The annual number of Amphiprion latezonatus clutches per female ranged from 1 to 14 (mean $8.0 \pm$ $1.52 \mathrm{SE}$; Table 2). Annual fecundity per pair was esti- mated at 10300 to 33140 eggs per female, with a mean of $18083( \pm 4386.1 \mathrm{SE})$ eggs per female. The number of eggs per clutch ranged from 1496 to 2508 eggs (mean $=1865$ $\pm 258.5 \mathrm{SE}$ ) (Table 2). Total A. latezonatus egg production peaked during January and February, although the mean monthly clutch size of $A$. latezonatus showed no consistent seasonal trends (Fig. 4).

Amphiprion akindynos pairs produced an estimated 814 to 2463 eggs per clutch (mean $1598 \pm 131.87 \mathrm{SE}$ ) and between 2 to 15 clutches (mean $6.7 \pm 1.00 \mathrm{SE}$ ) annually (Table 3). Annual egg production of $A$. akindynos ranged from 2160 to 26890 eggs per female (mean $=11370 \pm 2117.7 \mathrm{SE}$ ) (Table 3). Although mean annual egg production of $A$. akindynos pairs was almost half that of $A$. latezonatus, an unpaired $t$-test detected no significant difference in the mean annual production of eggs between $A$. akindynos and $A$. latezonatus pairs $(\mathrm{df}=18 ; t=$ $-1.514 ; p=0.147$ ), reflecting the high variability in clutch sizes among pairs. Consistent with $A$. latezonatus, the total number of eggs produced by $A$. akindynos per lunar month declined in cooler months, although the size of deposition areas did

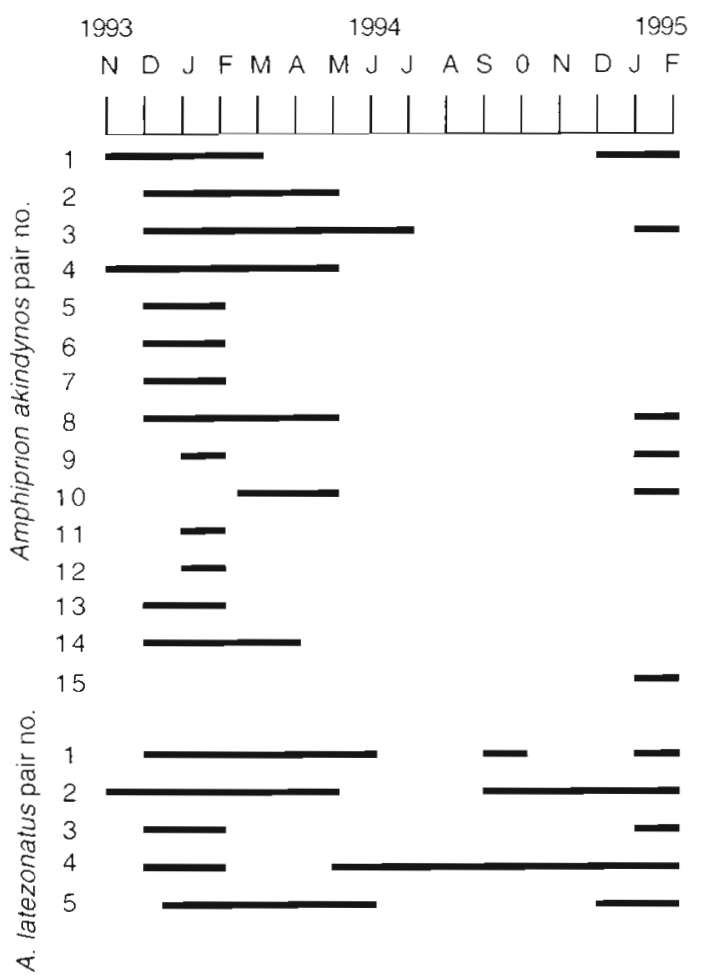

Fig. 3. Length of spawning season in breeding pairs of anemonefishes at Julian Rocks 
Table 1. Spawning regularity in pairs of (A) Amphipnon latezonatus and (B) A. akindynos within each quarter of the lunar month. Presented are the pair numbers that were observed to have egg clutches within each quarter of the lunar cycle. 'Total' is the total number of clutches observed within each lunar month over 14 lunar months. Dates given as day/month/year

\begin{tabular}{|c|c|c|c|c|}
\hline \multirow[t]{2}{*}{$\begin{array}{l}\text { Lunar } \\
\text { month }\end{array}$} & \multicolumn{4}{|c|}{$\begin{array}{c}\text { Pair number observed with an egg clutch } \\
\text { within each lunar quarter }\end{array}$} \\
\hline & New moon & 2nd & Full moon & 4 th \\
\hline \multicolumn{5}{|c|}{ (A) Amphiprion latezonatus } \\
\hline $27 / 1 / 94$ & $1,2,4$ & 1,3 & 2,5 & 1 \\
\hline $26 / 2 / 94$ & 5 & $1,2,3,4,5$ & - & $1,3,4$ \\
\hline $27 / 3 / 94^{b}$ & - & 1,5 & - & 1 \\
\hline $26 / 4 / 94$ & - & 5 & 5 & - \\
\hline $25 / 5 / 94$ & $1,2,4,5$ & - & - & - \\
\hline $24 / 6 / 94$ & 1,4 & - & - & - \\
\hline $24 / 7 / 94$ & 4 & - & - & - \\
\hline $22 / 8 / 94$ & 4 & - & - & - \\
\hline $21 / 9 / 94$ & 4 & 1,2 & $=$ & 4 \\
\hline $20 / 10 / 94$ & - & - & - & 1,2 \\
\hline $19 / 11 / 94$ & 4 & 5 & - & 5 \\
\hline $18 / 12 / 94$ & - & - & - & $2,3,4,5$ \\
\hline $16 / 1 / 95$ & $3,4,5$ & 1 & 1,3 & 4,5 \\
\hline $16 / 2 / 95$ & - & - & - & - \\
\hline Total & 18 & 19 & 5 & 18 \\
\hline \multicolumn{5}{|c|}{ (B) Amphiprion akindynos } \\
\hline $27 / 1 / 94$ & $4,14,1,2,8$ & $\begin{array}{c}14,3,1,6 \\
7,13,12\end{array}$ & $\begin{array}{l}4,2,8,5 \\
9,13,12\end{array}$ & $1,8,7,13$ \\
\hline $26 / 2 / 94$ & $4,2,9,10$ & $\begin{array}{l}1,2,5,7 \\
9,13,11\end{array}$ & $4,1,2,5,10$ & $\begin{array}{c}14,3,8 \\
9,1.3\end{array}$ \\
\hline $27 / 3 / 94$ & $1,8,13$ & $1,2,8,9,3$ & $4,5,7$ & $14,3,1,2$ \\
\hline $26 / 4 / 94$ & $8,9,10$ & 2,7 & $4,14,8,9,10$ & - \\
\hline $25 / 5 / 94$ & $2,1.0$ & $4,3,8,9,13$ & 7 & - \\
\hline $24 / 6 / 94$ & - & - & - & - \\
\hline $24 / 7 / 94$ & - & 3 & - & - \\
\hline $22 / 8 / 94$ & - & - & - & - \\
\hline $21 / 9 / 94$ & - & - & - & - \\
\hline $20 / 10 / 94$ & - & - & - & 8 \\
\hline $19 / 11 / 94$ & - & - & - & - \\
\hline $18 / 12 / 94$ & 8 & 1,9 & $1,8,5,6$ & $4,1,5$ \\
\hline $16 / 1 / 95$ & $8,6,9$ & $1,9,10$ & $14,1,8,15$ & $14,8,9,10$ \\
\hline $16 / 2 / 95$ & $7,15,13$ & - & 13 & - \\
\hline Total & 28 & 36 & 4.1 & 24 \\
\hline
\end{tabular}

not vary seasonally (Fig 5). This result reflects the larger number of clutches produced during January and February 1994 compared to other months (Fig. 2).

\section{DISCUSSION}

The fecundity and timing of spawning of Amphiprion akindynos and A. latezonatus at Julian Rocks were similar to those described for temperate Japanese assemblages of $A$. clarkii, but were substantially different from tropical congeners. Although fecundity varied

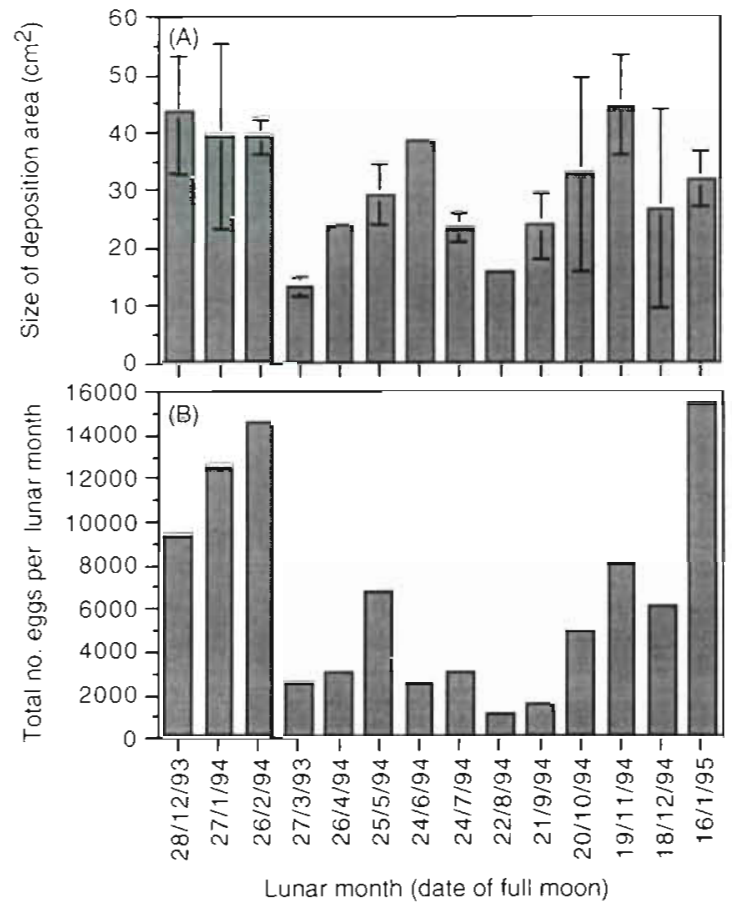

Fig. 4. (A) Mean maximum clutch size ( $\pm S E$ ), and (B) total number of eggs produced by Amphiprion latezonatus pairs (pooled) over a 13 mo period

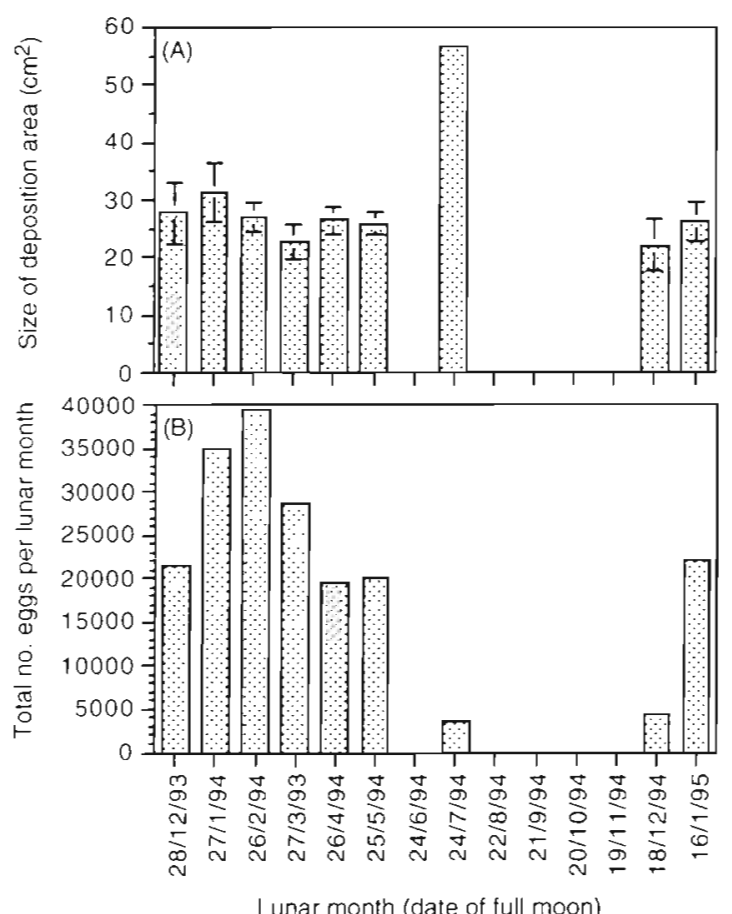

Fig. 5. (A) Mean maximum clutch size ( $\pm S E$ ), and (B) total number of eggs produced by Amphiprion akindynos pairs (pooled) over a 13 mo period 
Table 2. Estimates of fecundity in Amphiprion latezonatus at Julian Rocks

\begin{tabular}{|lcccc|}
\hline Pair no. & $\begin{array}{c}\text { Annual no. } \\
\text { clutches }\end{array}$ & $\begin{array}{c}\text { Deposition area } \\
{\left[\bar{x}( \pm \text { SE }) \mathrm{cm}^{2}\right]}\end{array}$ & $\begin{array}{l}\text { eggs clutch } \\
{[\bar{x}( \pm \mathrm{SE})]}\end{array}$ & $\begin{array}{c}\text { Annual egg } \\
\text { production }\end{array}$ \\
\hline 1 & 14 & $39.9( \pm 0.12)$ & $2367( \pm 721.0)$ & 33140 \\
2 & 7 & $21.8( \pm 0.29)$ & $1496( \pm 321.8)$ & 10470 \\
3 & 5 & $25.1( \pm 0.13)$ & $2005( \pm 702.1)$ & 10030 \\
4 & 9 & $36.8( \pm 0.24)$ & $2508( \pm 259.2)$ & 22570 \\
5 & 5 & $29.8( \pm 0.14)$ & $2028( \pm 390.3)$ & 14200 \\
$\bar{x}( \pm \mathrm{SE})$ & $8.0( \pm 1.5)$ & $27.7( \pm 4.11)$ & $1865( \pm 258.5)$ & $18083( \pm 4386.1)$ \\
& & & & \\
\hline
\end{tabular}

Table 3. Estimates of fecundity in Amphiprion akindynos at Julian Rocks

\begin{tabular}{|c|c|c|c|c|}
\hline Pair no. & $\begin{array}{l}\text { Annual no. } \\
\text { clutches }\end{array}$ & $\begin{array}{c}\text { Deposition area } \\
{\left[\bar{x}( \pm \mathrm{SE}) \mathrm{cm}^{2}\right]}\end{array}$ & $\begin{array}{l}\text { No. eggs clutch }{ }^{-1} \\
{[\bar{x}( \pm \text { SE })]}\end{array}$ & $\begin{array}{l}\text { Annual egg } \\
\text { production }\end{array}$ \\
\hline 1 & 11 & $40.42( \pm 5.01)$ & $2060( \pm 252.6)$ & 22660 \\
\hline 2 & 7 & $26.04( \pm 2.86)$ & $2006( \pm 148.2)$ & 14040 \\
\hline 3 & $5^{\text {a }}$ & $37.87( \pm 8.72)$ & $1867( \pm 476.8)$ & 9330 \\
\hline 4 & 8 & $35.34( \pm 3.14)$ & $2463( \pm 186.2)$ & 19700 \\
\hline 5 & 6 & $14.55( \pm 1.89)$ & $906( \pm 148.6)$ & 5430 \\
\hline 6 & $2^{b}$ & $12.69( \pm 4.23)$ & $1079( \pm 287.3)$ & 2160 \\
\hline 7 & 7 & $24.82( \pm 3.36)$ & $1576( \pm 269.8)$ & 11030 \\
\hline 8 & 15 & $29.23( \pm 2.30)$ & $1793( \pm 325.4)$ & 26890 \\
\hline 9 & 11 & $28.83( \pm 3.20)$ & $1875( \pm 222.0)$ & 20630 \\
\hline 10 & 8 & $17.52( \pm 2.88)$ & $1121( \pm 184.3)$ & 8970 \\
\hline 11 & 2 & $21.99( \pm 6.28)$ & $1407( \pm 401.8)$ & 2810 \\
\hline 12 & $3^{c}$ & $15.97( \pm 6.35)$ & $1021( \pm 406.6)$ & 3060 \\
\hline 13 & 9 & $28.17( \pm 4.63)$ & $1804( \pm 227.9)$ & 16230 \\
\hline 14 & 4 & $15.01( \pm 2.23)$ & $814( \pm 175.6)$ & 3260 \\
\hline 15 & 2 & $34.01( \pm 9.97)$ & $2176( \pm 638.4)$ & 4350 \\
\hline $\bar{x}( \pm \mathrm{SE})$ & $6.7( \pm 1.0)$ & $25.50( \pm 2.33)$ & $1598( \pm 131.9)$ & $11370( \pm 2117.7)$ \\
\hline \multicolumn{5}{|c|}{$\begin{array}{l}\text { 'Mate lost in late December 1995, replaced immediately by } \\
\text { Amphiprion akindynos } \\
\text { bMate loss in mid August 1994, replaced mid October } 1994 \\
\text { 'Mate loss in mid August 1994, replaced late January } 1995\end{array}$} \\
\hline
\end{tabular}

greatly among individuals of the same species, $A$. akindynos and A. latezonatus, like temperate $A$. clarkii, had higher annual fecundity and larger clutch sizes than tropical congeners (Table 4). Although higher fecundity with increasing latitude is common among terrestrial vertebrates (Giesel 1976) and marine fishes (Bell 1976 , Thresher 1988), explanations for this pattern are varied (Giesel 1976) and largely untested. It is likely that a number of environmental factors that characterise high latitude areas determine this pattern (Moyer 1980).

The timing of spawning is generally thought to be determined by optimal environmental conditions allowing the greatest survival and fitness for larvae, juveniles and/or adults (Robertson 1991). Over seasonal time scales, Amphiprion akindynos and $A$. latezonatus both had peak fecundity in January and February, coinciding with the annual maximum peak water temperature. Larval and juvenile fitness/survivorship may be enhanced at warm water temperatures due to greater food availability (Allen 1975, Russell et al. 1977), higher growth rates (Ochi 1986), and a reduction in temperature related stress (Moyer 1980) compared to cool water periods. Spawning more frequently at higher water temperatures may also be

Table 4. Clutch size and estimated annual egg production of anemonefish pairs in warm temperate and tropical localities. nd: no data

\begin{tabular}{|c|c|c|c|c|}
\hline Species & Location & Annual no. clutches & No. eggs clutch ${ }^{-1}$ & Annual no. eggs pair ${ }^{-1}$ \\
\hline \multicolumn{5}{|l|}{ Tropical } \\
\hline A. melanopus ${ }^{a}$ & $\operatorname{Guam}\left(13^{\circ} \mathrm{N}\right)$ & 19.78 & $200-400$ & 7200 \\
\hline A. bicinctus ${ }^{\text {b }}$ & Red Sea & nd & $600-1600$ & 9600 \\
\hline A. chrysopterus ${ }^{\mathrm{C}}$ & Eniwetok $\left(11^{\circ} \mathrm{N}\right)$ & $8-9$ & $\sim 400$ & $3000-5000$ \\
\hline A. perideraion ${ }^{c}$ & Eniwetok & $8-9$ & $300-700$ & $2000-4000$ \\
\hline A. percula and A. clarkii ${ }^{\mathrm{d}}$ & Tropical aquarium & nd & $400-1500$ & nd \\
\hline A. percula ${ }^{\mathrm{e}}$ & Tropical aquarium & 13 & 200 & 5000 \\
\hline \multicolumn{5}{|c|}{ Subtropical/warm-temperate } \\
\hline A. clarkiif & Miyake-Jima $\left(34^{\circ} \mathrm{N}\right)$ & $6-8$ & $1000-2500$ & $8000-17500$ \\
\hline A. clarkii ${ }^{\mathrm{g} h}$ & Shiko-ku Is. $\left(33^{\circ} \mathrm{N}\right\}$ & $2-9$ & $1600-5400$ & $11000-15000$ \\
\hline A. akindynos ${ }^{\mathrm{i}}$ & Julian Rocks $\left(27^{\circ} \mathrm{S}\right)$ & $2-15$ & $700-5025$ & $2810-26890$ \\
\hline A. latezonatus ${ }^{\mathrm{i}}$ & Julian Rocks & $1-14$ & $800-3870$ & $10470-33140$ \\
\hline \multicolumn{5}{|c|}{ 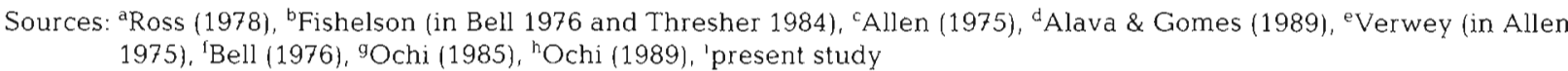 } \\
\hline
\end{tabular}


advantageous to breeding adults. Since the incubation time of embryos declines with increasing temperature in Amphiprion (Bell 1976), parental care of a single clutch, and the associated metabolic costs to adults, may be reduced substantially by spawning more frequently at high water temperatures.

Despite the coincident seasonal peak in fecundity of these species, the length of breeding seasons varied greatly between species within the same locality. Like Amphiprion clarkii assemblages in temperate Japan (Bell 1976, Moyer \& Bell 1976, Moyer 1980, Ochi 1985), the spawning season of the local $A$. akindynos assemblage was restricted to summer and autumn, contrasting with the year-round spawning of A. latezonatus. A. latezonatus is endemic to sub-tropic areas along the east coast of Australia (Allen 1991), hence year-round spawning may be a physiological and ecological adaptation to cool and unstable sea temperatures. By contrast, A. akindynos is a primarily tropical species, hence reproduction may be impaired at cooler sea temperatures.

Short-term spawning patterns also appear to vary latitudinally. Studies to date indicate that tropical anemonefishes throughout the Indo-Pacific region have cyclic spawning patterns that occur within $7 \mathrm{~d}$ of the full moon (Allen 1975, Ross 1978, Fricke in Thresher 1984). Although temperate assemblages of Amphiprion clarkii display cyclic spawning patterns in some years, this pattern is often not repeated in the following years (Bell 1976, Ochi 1985). The results of this study show that of the $129 \mathrm{~A}$. akindynos egg clutches observed at Julian Rocks, only $77(60 \%)$ were laid within $7 \mathrm{~d}$ of the full moon. In contrast, $A$. latezonatus had approximately equal numbers of spawnings in the first, second and fourth quarters, but only $\sim 8 \%$ of spawnings occurred in the third lunar quarter (the quarter following the full moon). These results suggest that anemonefish spawnings at high latitudes are generally less cyclic and less predictable over time than in the tropics.

Latitudinal variations in the strength of lunar spawning patterns may be related to the temporal stability of water temperatures. In tropical regions, where seasonal variations in water temperature are unlikely to be major constraints on larval and post-larval survivorship (Robertson 1991), synchronised spawning that coincides around the full moon may provide several potential benefits to both larvae and adults (Allen 1975, Robertson 1991). In contrast, water temperatures at high latitudes are highly seasonal and are generally unstable and unpredictable over relatively short time periods (Richardson unpubl. data). Rapid short-term changes in water temperature result in embryo incubation times varying from 6 to $12 \mathrm{~d}$ (Bell 1976, D. Richardson unpubl.), thus the timing of hatching would be unpredictable and not synchronised with associated lunar patterns, such as tidal currents and the light intensity of the moon (Ochi 1985). Furthermore, since anemonefishes spawned continuously during peak Austral water temperatures, lunar spawning patterns may be over-ridden to allow for increased reproductive output when conditions are presumably optimal.

In conclusion, the similarity in spawning patterns of Amphiprion akindynos and A. latezonatus to temperate assemblages of $A$. clarkii is consistent with the hypothesis that environmental pressures associated with high latitude environments modify the reproductive biology of anemonefishes. Further experimental studies examining the reproductive biology of a single anemonefish species over a broad-scale latitudinal gradient are needed to determine the environmental controls regulating these patterns.

Acknowledgements. Thank you to our dive buddies, particularly C. Gehrig and G. Davey, for their assistance. This study was partly funded by the Centre for Coastal Management and grants to V.H. and P.H.

\section{LITERATURE CITED}

Alava VR, Gomes LAO (1989) Breeding marine aquarium an1mals: the anemonefish. Naga ICLARM Q July 1989:12-13 Allen GR (1975) Anemonefishes: their classification and biology. TFH, Neptune City

Allen GR (1991) Damselfishes of the World. Mergus, Melle

Bell LJ (1976) Notes on the nesting success and fecundity of anemonetish Amphiprion clarkil at Miyake-Jima, Japan Jap J Ichthyol 22:207-211

Giesel JT (1976) Reproductive strategies as adaptations to life in temporally heterogeneous environments. Annu Rev Ecol Syst 7:57-79

Moyer JT (1980) Influence of temperate waters on the behavior of the tropical anemonefish Amphiprion clarkii at Miyake-Jima, Japan. Bull Mar Sci 30:261-272

Moyer JT, Bell LJ (1976) Reproductive behavior of the anemonefish Amphiprion clarkii at Miyake-Jima, Japan. Jap J Ichthyol 23:23-32

Ochi $H$ (1985) Temporal patterns of breeding and larval settlement in a temperate population of the tropical anemonefish, Amphiprion clarkii. Jap J Ichthyol 32 $248-257$

Ochi H (1986) Growth of the anemonefish Amphiprion clarkii in temperate waters, with special reference to the influence of settling time on the growth of 0-year olds. Mar Biol 92:223-229

Ochi $H$ (1989) Mating behavior and sex change of the anemonefish, Amphiprion clarkii, in the temperate waters of Japan. Environ Biol Fish 26:257-275

Richardson DL, Harriott VJ, Harnson PL (1997) Distribution and abundance of giant sea-anemones (Actiniaria) in subtropical Eastern Australian waters. Mar Freshwat Res 48: $59-66$

Robertson DR (1991) The role of adult biology in the timing of spawning of tropical reef fishes. In: Sale PF (ed) The ecology of fishes on coral reefs. Academic Press, Sydney, p $356-386$ 
Robertson DR, Green DG, Victor BC (1988) Temporal coupling of production and recruitment of larvae of a Caribbean reef fish. Ecology 69:370-381

Ross RM (1978) Reproductive behavior of the anemonefish Amphiprion melanopus on Guam. Copeia 1978: $103-107$

Russell BC, Anderson GRV, Talbot FH (1977) Seasonality and

This article was submitted to the editor recruitment of coral reef fishes. Aust J Mar Freshwat Res 28:251-258

Thresher RE (1984) Reproduction in reef fishes. TFH, Neptune City

Thresher RE (1988) Latitudinal variation in egg sizes of tropical and subtropical North Atlantic shore fishes. Environ Biol Fish 21:17-25

Manuscript received: June 17, 1997

Accepted: July 9, 1997 